\title{
MOBILE TICKET LIFECYCLE MANAGEMENT: CASE STUDY OF PUBLIC TRANSPORT IN LATVIA
}

\author{
Nikolajs Bumanis ${ }^{1}$, Gatis Vitols ${ }^{2}$, Irina Arhipova ${ }^{1}$, Ivars Mozga ${ }^{2}$ \\ ${ }^{1}$ Ltd "Mobilly", Latvia; ${ }^{2}$ Latvia University of Agriculture \\ gatis.vitols@1lu.lv, nikolajs.bumanis@1lu.lv, irina.arhipova@1lu.lv, ivars.mozga@1lu.lv
}

\begin{abstract}
There are solutions in the market that enable brand holders to combine their serviceswithother suppliers of goods or services. However, there is no unified technological solutionavailable for e-commerce purchasing object management. Purchasing objects are objects that are generated automatically or manually createdas a result of the transaction, for example, a bus ticket, travel insurance payment, concert ticket orthird party liability insurance. Management of purchasing objects is an important e-commerce process for all involved parties. Now a variety of payment methods and information systems are available in the market that allows generating purchasing objects. E-tickets are an example of the purchasing objects, which are rapidly being introduced for use. Electronic ticket management is increasingly entrusted to mobile devices and applications. Market analysis shows that e-ticket management becomes more complicated because it is related to different systems, applications and interfaces in the transport sector. This study analyses the mobile ticket life-cycle management problems that are being solved in the development of the service providers' mutual integration solution architecture model. The unified public transport service scenario was developed, which consists of purchasing object generation, storing and transporting to service providers, transaction processors and customers. The developed purchasing object management model provides customers with opportunity to manage the financial transaction documents, while service providers will facilitate the document turnover and improve the business process. The proposed model has been piloted on a joint stock company micro-payment system infrastructure, integrating Latvian Railway external services. The study was conducted in the framework of Latvia, and is aimed to improve e-commerce solutions in Latvia.
\end{abstract}

Keywords: e-ticket, m-ticket, e-commerce solution.

\section{Introduction}

Rapid developments in information technology transform the way various businesses are executed. With maturing of the technology and fast distribution of smartphones, more and more businesses go partially or fully mobile. However, business preparation for mobile e-commerce includes an important step - creating mobile service that is convenient for merchants and is user friendly. Data show that in Finland after installation of mobile applications during the next month only $35 \%$ are continued to be used [1].

Another important step is to include payment methods that users recognize and can apply, such methods include or are compatible with local internet banks, and use recognised services such as PayPal, Square, Stripe or others. IT companies develop special applications to support mobile payments such as Google Wallet and Apple Pay. These applications allow storing payment data in special protected profile, so whenever the user needs to pay for the product or service, there is no need to re-enter payment information. Such special applications are rather new solutions and still unavailable in many countries [2]. Some companies, such as Amazon, also invest in development of new payment systems. However, corporations, such as Apple, Google, Tencent, Baidu, Alibaba and Paypal, recognize that mobile payments will be an important part of e-commerce solutions in the future [3].

Transportation industry organizations are trying to substitute printed ticketing with electronic ticketsusing different technologies for multiple yearsalready, including separate smartcards [4-6], multiple application SIM cards [7] and mobile tickets managed by mobile applicationintegrated with mobile payment infrastructure [8].Until 2015 mobile payments and mobile e-commerce in the Baltic states were poorly supported and executed [9]. However, more companies develop infrastructure that allows execution of mobile payments and supports mobile transaction object management, including transportation ticket or e-ticket management. In Latvia, micropayments are one of the mechanisms that support mobile ticket management.

This article addresses e-ticket management issues and solutions using mobile platforms and give insights to integration of mobile e-ticket management into information systems of Latvian Railways.Etickets in Latvia can be purchased from multiple sources, however, we will address Mobilly mobile 
application and webpage service as the main research object as to provide a definite example of the current situation with electronic document lifecycle and management.

\section{E-ticket lifecycle and management}

Transportation systems are one of the frontiers in application of e-ticketing. Paper tickets are replaced by electronic counterparts. The places as London, San Paulo, Singaporeand others already use e-tickets for a while [10]. Usually the RFID technology is used and e-ticket or multiple ticket information is included into separate smartcard. With introduction of the NFC technology, which can be named as the front-end RFID solution into mobile devices, users do not need to carry a separate RFID card, instead smartphone with special application can be used.However, RFID introduces another problem, correlating with definition of mobile itself - the user must put the device near a contact with Point of Sale terminal to perform a transaction [11].

Truly mobile e-tickets are those purchased away from physical Point of Sale terminals and used only as purchase verification documents. Therefore, we can say that e-tickets are basically electronic documents stored for later use.

There are currently multiple types of electronic documents used in public transportation in Latvia. These document types can be described by systems and devices that store them. Electronic documents in the framework of the Latvian public transportation system are stored in transportation service merchants provided profile systems, and can be used from either a mobile device or smartcard.Almost all electronic documents, excluding transaction documents for transfer transactions, can be accessed by the user either from a mobile device, smartcard or webpage service.

Electronic documents in mobile applicationsare usually in QR code or image, including barcode, format. QR code provides interactivity and allows transportation service attendants to validate the ticket by using a contactless scanner [12], whereas the image format removes this requirement but takes longer time to validate manually by the attendant.

In case of smartcards, the organization responsible for smartcard type e-tickets deployment, for example, subscription e-tickets, must perform e-ticket conversion to binary data, then generate a script, performed by Points of Sale terminals, and put the smartcard in STOPLIST so the script can be loaded by Points of Sale in the moment the smartcard is used.

\section{Purchasing objectgeneration in the framework of the Latvian Railway infrastructure}

Mobile e-tickets for Latvian Railway service can be purchased using mobile application (Fig. 1) or webpage service provided by Mobilly. Client, mobile application or webpage service usersare able to define the route by choosing the start and final destination, after which the list of possible departure times is shown. Choosing one directs the client to payment authorization. At this stage the mobile eticket as a document is at the initiation stage, containing all data for particular transportation. As for Mobilly provided payment authorization the client must pay using Mobilly account funds. These funds can be deposited using the payment methods provided by the banks. Mobilly also provides a possibility to use banking accounts for automatic fund deposition. After the payment is done the Mobilly profile system collects all necessary data for e-ticket generation and performs it. Generated documents, including e-ticket, are stored in the Mobilly profile system and are sent to the client's mobile application, if used, andor client's e-mail if stated by the client. Currently Mobilly does not provide e-tickets for smartcards, however, it is important to mention that smartcards can store only binary data, therefore e-tickets, even if generated with unified format, must be converted. Smartcards store e-tickets as binary data in envelopes.

After the initial e-ticket purchase the only management of e-tickets performed by Mobilly is to store the e-ticket, whereas the client must store the e-ticket for transportation service to provide it as an evidence document. All transaction documents are kept at the Mobilly profile system, and only the purchase order with the date stated is available to the client.

The transportation of purchase documents is performed using web service provided by Latvian Railways connecting the Mobilly profile system and the Latvian Railways client management system. Purchase document copies, in this case - the purchase order, receipt and also transit transaction documents are transported if the fund deposition was performed during payment authorization. 




Fig. 1. Latvian Railways e-ticket generation flow

\section{Proposed unified document structure and management}

The way Mobilly conducts electronic document management is limited in the aspect of the client having more than one user profile used for electronic documents. The real world situation often requires the user to have multiple profiles from multiple service providers[13]. Therefore, the application of unified document structure, which can be used by multiple profile systems and allows the user to combine functionality of multiple profiles, is proposed. Transaction document is an abstract distributed document object, which circulates between different integrated profile systems. Each document is created for a particular document type and document class (Fig. 2).
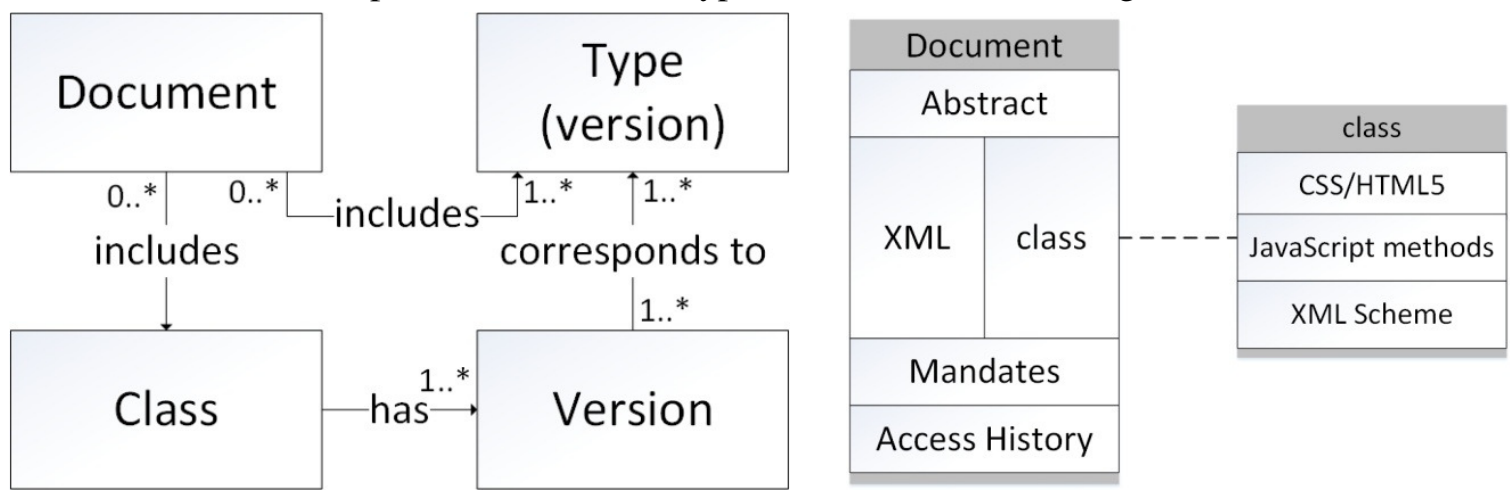

Fig. 2. Document class, type association and document architecture 
The document class has versions, where each class version describes document XML part and JavaScript methods. Each of the class versions corresponds to a particular document type. It is also important to mention, that the multiple class version may correspond to one document type and vice versa, where the document type determines the document affiliation to particular service or product.Each document is stored in one profile system, but can be accessed and managed from multiple profiles. Therefore, we introduce delimitation of document stored in the profile system from use-only profile systems by two entities - original document and snapshot.

Original document is a document, which is stored at the profile system considered to be this document's initial storage place. This profile system is also called the document class author, defining such document components as XML, JavaScript methods and CSS/HTML5.Snapshot, on the other hand, is the original document copy created for particular client's session request, and is used for accessing and management purposes. The main document object's components are the following.

- Abstract - unified data set used for document identification; includes such attributes as the identification number, version, previous version if exists, type, parent document link if exists, child document link if exists, author (user), initiation system identification number, list of profile systems to inform in case any changes to the document are done, original storage system identification number, snapshot entity identification number.

- $\mathrm{XML}$ - document content in XML format.

- Class - set of rules for document creation, describing the content structure in CSS/HTML5 format, document functionality in form of JavaScript methods, and XML Scheme - XSD, for the document content validation.

- Mandates - set of authorization mandates, used to control access rights on a particular document. In case of multiple profiles, the user may have client privileges with different authorization levels. For example, sensitive electronic data such as one in the medical field must not be accessed from client profiles only using the mobile phone as authentication data. In this scenario the bank authorization identity provider may be used.

- Access History - history of all changes done to the document and access log.

Generation of the document (Fig. 3) is performed by the initiation system - profile system, which the profile user is currently using to access/create/manage the document, firstly requesting the document class component from the document class author profile system. After the initiation system receives class components, it initializes snapshot generation. Any type of document can be generated, such as the purchase order, payment order or even report. The generated snapshot is then sent to the original document storage profile system, which in return generates the document's unique identification number. Updated with the identification number the snapshot is sent back to the initiation system, if needed.

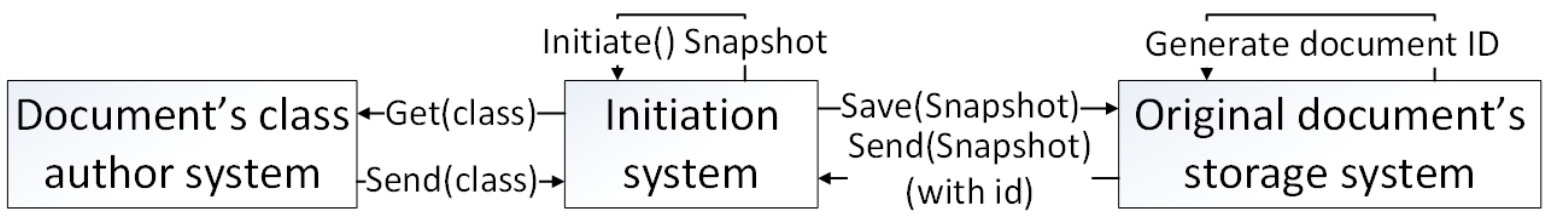

Fig. 3. Generation of snapshot type electronic document

We introduce a possibility to use a different storage profile system other than, but delegated by the document class author's profile system, to create more flexibility of document management.The transportation for both snapshots and original documents is performed using a single messaging system, API of which is integrated into the profile systems. Any document, necessary to be coped, is created new as an original document with reference to the previous original document, thus enabling a mechanism similar to block chain - every document has a parent and a child entity, where the first original document purchase object "purchase order" will have the purchase request as the parent entity. The proposed electronic document architecture and management principles allow management of particular documents, stored in one profile system, using the client profile from the second profile system, whereas the document structure in form of its class is dictated by the third profile system. This scheme provides a possibility for parenting management from the personal client profile, without the 
need to access the child's account. It is important to mention, that parenting is an option provided by the document mandates.

\section{Proposed model implementation results in the Latvian Railway infrastructure}

The proposed model was implemented into the Mobilly system in 2016. At the same year the Mobilly solution has been introduced to Latvian Railways services. With promotion of the ticket purchase options, including purchasing the mobile ticket using Mobillyapplication, there is a seen increase in mobile ticket sales.

Fig. 4 shows comparison ofMobilly ticket sales for two leading mobile operation systems[14] iOS and Android using Mobilly application.There is a seen growth of the e-ticket count, purchased using these two mobile applications. During the last ten months the overall average purchased e-ticket count per month increased by at least 3000 entities. The result of the Latvian Railways case is promising, and shows that the m-commerce market segment in Latvia is growing.

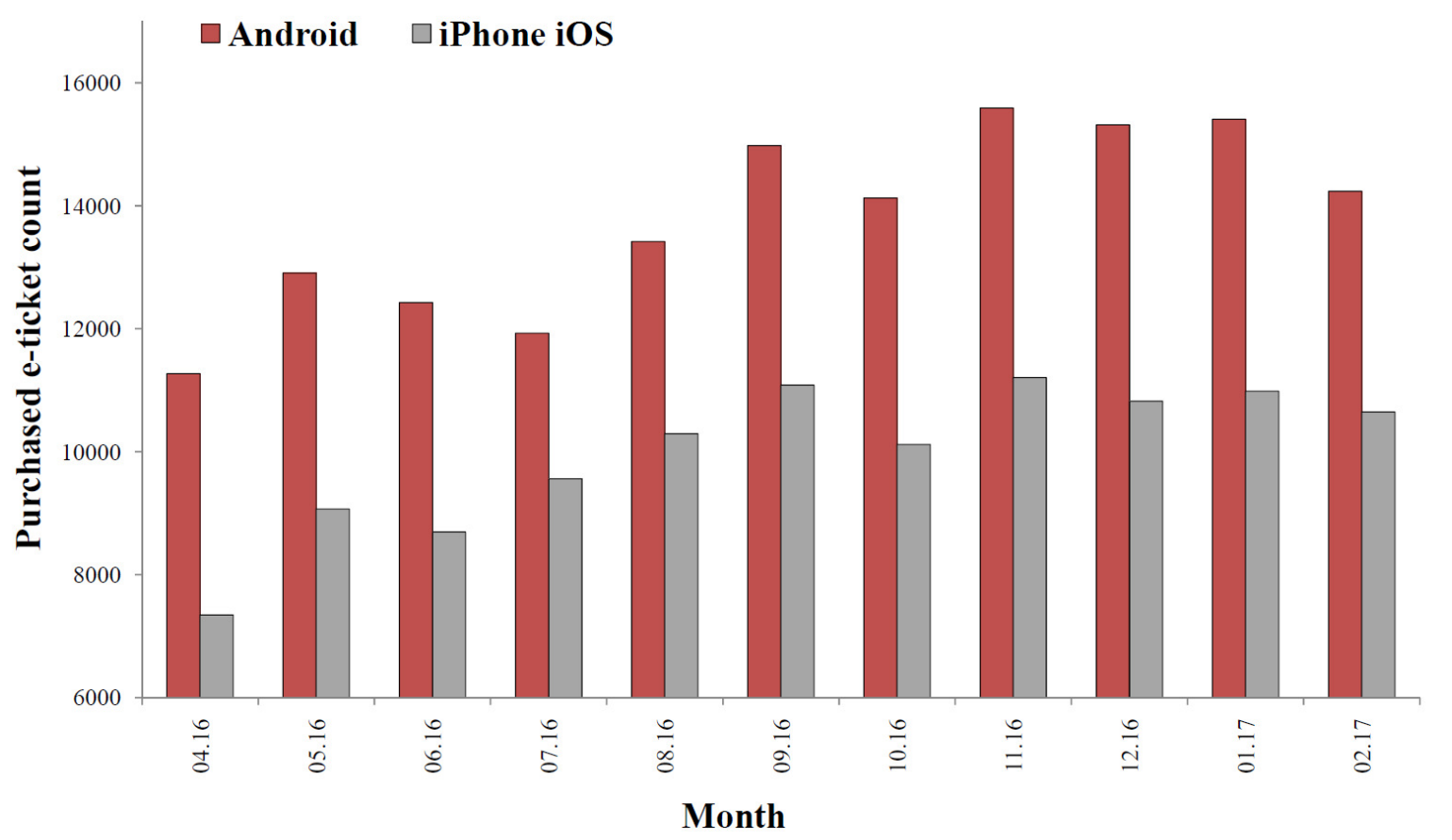

Fig. 4. Mobile application operating system comparison to purchased e-ticket count

The overall ticket count purchased in 2016 for Latvian Railways summarizes up to 15 million, $1.5 \%$ of them were m-tickets. Mobile tickets also are available from multiple information systems and applications, such as 1188.lv and Bezrindas.lv services. However, they are mostly used as printed version sources, and the amount from other services is less than 3 thousand per month. During the model realization and growth of e-ticket market, a new method of pricing was introduced by Latvian Railways, which specifies pricing for particular routes, increasing or decreasing the price according to the distance between stops and core destinations.

\section{Conclusions}

1. Security difficulties created by integration of multiple profile systems are easily dealt with using licensed identity providers and a separated session manager system for token, identity and session management.

2. Unified document structure, which includes both the content and functionality, specified by authorized party is able to achieve cross branch e-commerce collaboration, thus bringing electronic documents for the masses.

3. Using this new document structure for Latvian Railways e-tickets will allow easier distribution for the users, as they will not need to login into different client profiles for a single ticket purchase, and will have an option to use single client profile for all their e-service needs. 
4. The overall ticket count purchased in 2016 for Latvian Railways summarizes up to 15 million, $1.5 \%$ of them were m-tickets with shown growth.

\section{Acknowledgements}

The research leading to these results has received funding from the research project "Competence Centre of Information and Communication Technologies" of EU Structural funds, contract No. 1.2.1.1/16/A/007 signed between IT Competence Centre and Central Finance and Contracting Agency, Research No. 1.4 "Development of personified transaction document management model". More information at http://www.itkc.lv/?lang=en.

\section{References}

1. Ipsos, "Our Mobile Planet: Finland - Understanding the Mobile Consumer," 2012.

2. Kerris N., Muller T. "Apple Announces Apple Pay," 2014.

3. Melkis D. "Mobile payments - bait for customers (Mobilie maksājumi - ēsma pircējiem)," Dienas bizness, Riga, p. 4, 2014.

4. Vitols G., Bumanis N., Smirnova J., Salajevs V., Arhipova I., Smits I. "Multi-payment solution for smartlet applications," in ICEIS 2015 - Proceedings of the 17th International Conference on Enterprise Information Systems, 2015, vol. 2, pp. 668-673.

5. Mut-Puigserver M., Payeras-Capellà M.M., Ferrer-Gomila J.-L., Vives-Guasch A., CastellàRoca J. "A survey of electronic ticketing applied to transport," Comput. Secur., vol. 31, no. 8, pp. 925-939, Nov. 2012.

6. Payeras-Capellà M.M., Mut-Puigserver M., Ferrer-Gomila J.-L., Castellà-Roca J., VivesGuasch A. "Electronic Ticketing: Requirements and Proposals Related to Transport," 2015, pp. 285-301.

7. Jog A., Kayiran O., Kesten T., Pattnaik A., Bolotin E., Chatterjee N., Keckler S.W., Kandemir M.T., Das C.R. "Anatomy of GPU Memory System for Multi-Application Execution," in Proceedings of the 2015 International Symposium on Memory Systems - MEMSYS '15, 2015, pp. 223-234.

8. Fan K., Song P., Du Z., Zhu H., Li H., Yang Y., Li X., Yang C. "NFC Secure Payment and Verification Scheme for Mobile Payment," 2016, pp. 116-125.

9. Igaune S. "For Latvia mobile wave is still ahead (Latvijā mobilo maksājumu vilnis vēl priekšā)," Dienas bizness, Riga, pp. 4-5, 2014.

10. Gudymenko I. "A Privacy-Preserving E-Ticketing System for Public Transportation Supporting Fine-Granular Billing and Local Validation" in Proceedings of the 7th International Conference on Security of Information and Networks - SIN '14, 2014, pp. 101-108.

11. Ceipidor U.B., Medaglia C.M., Marino A., Morena M., Sposato S., Moroni A., Di Rollo P., La Morgia M. "Mobile ticketing with NFC management for transport companies. Problems and solutions," in 2013 5th International Workshop on Near Field Communication (NFC), 2013, pp. 1-6.

12. Lin P.-Y., Chen Y.-H. "QR code steganography with secret payload enhancement," in 2016 IEEE International Conference on Multimedia \& Expo Workshops (ICMEW), 2016, pp. 1-5.

13. Bumanis N., Vitols G., Smits I., Smirnova J., Arhipova I., Salajevs V. "Service Oriented Solution for Managing Smartlets," Procedia Comput. Sci., vol. 43, no. 1, pp. 33-40, 2014.

14. IDC, "IDC: Smartphone OS Market Share 2016, 2015". 